\title{
Prevalence of Partial Edentulousness and Treatment needs in Rural Population of South India
}

\author{
1Javed Ashraf, ${ }^{2}$ Ashish R Jain, ${ }^{3}$ Padma Ariga, ${ }^{4}$ Deepak Nallaswamy
}

\begin{abstract}
Introduction: Oral disease creates a major public health burden worldwide and receives inadequate attention in many low- and middle-income countries (WHO 2003).
\end{abstract}

Aim: The aim of this study was to estimate the prevalence of tooth loss and treatment needs of a rural adult population in South India.

Materials and methods: A descriptive point prevalence survey was conducted in three rural districts of Tamil Nadu, South India. A total of 3,000 subjects with a mean age of 36.2 (standard deviation 13.02) years participated in a clinical examination and interview. They were divided into three groups based on age: Group I - 18 to 30 years, group II -31 to 50 years, and group III -51 to 80 years.

Results: The overall prevalence of tooth loss was $48.7 \%$. The most commonly occurring type of partial edentulousness was Kennedy's class III in maxilla comprising $23.3 \%$ followed by mandible $22.1 \%$. Mandibular first molar was the most common missing tooth. The prevalence of tooth loss was more in males $(58.2 \%)$ than females (41.8\%). Group III subjects had the highest incidence of tooth loss.

Conclusion: The prevalence of tooth loss in South Indian rural population was $48.7 \%$. The most common reason for tooth loss was dental caries which accounted for $50 \%$ followed by periodontal reasons $30 \%$ and others $10 \%$. Fixed type of prosthesis was the preferred type of restoration for all the individuals with tooth loss, but affordability was the major factor that determined the treatment of the patients.

Keywords: Partial edentulousness, Prevalence, Survey, Tooth loss pattern, Treatment needs.

How to cite this article: Ashraf J, Jain AR, Ariga P, Nallaswamy D. Prevalence of Partial Edentulousness and Treatment needs in Rural Population of South India. World J Dent 2017;8(3):213-217.

Source of support: Nil

Conflict of interest: None

\section{INTRODUCTION}

The presence (or) absence of teeth is a good indicator of oral health of an individual. ${ }^{1}$ Several studies have con-

1-4 Department of Prosthodontics, Saveetha Dental College and Hospitals, Chennai, Tamil Nadu, India

Corresponding Author: Ashish R Jain, Department of Prosthodontics, Saveetha Dental College and Hospitals Chennai, Tamil Nadu, India, Phone: +91442614439, e-mail: dr.ashishjain_r@yahoo.com clusively established the fact that oral health and general health are interdependent. ${ }^{2}$ Oral health is an important component of both overall health and quality of life. Oral disease creates a major public health burden worldwide and receives inadequate attention in many low- and middle-income countries [World Health Organization (WHO)]. ${ }^{3}$ Systemic conditions have oral manifestations that increase the risk of oral disease, which in turn is a risk factor for various systemic diseases.

Tooth loss affects the overall health and quality of life of an individual, causing reduced efficiency and function of the masticatory system and the appearance of the individual. By reduced chewing ability in individuals with tooth loss, diet and nutritional intake could probably be reduced..$^{2-5}$

The reasons for tooth loss may be due to dental caries, periodontal disease, traumatic accidents, impaction, orthodontics, supernumerary, preparation for radiotherapy, or even due to congenital and developmental disorders. ${ }^{6}$ The two most common causes of tooth loss in Asian population are dental caries and periodontal disease. ${ }^{7}$ Secondary reasons for tooth loss are restricted access to dental services, health systems, and lack of oral health care. ${ }^{8}$

Rural India accounts for $83.3 \%$ of the total population of India which accounts for majority of the population. The total population of Tamil Nadu is over seven million people and it contributes for $5.96 \%$ of the total population of India.

The aim of this study was to estimate the prevalence of tooth loss and treatment needs in the rural population of South India. Pattern of tooth loss was studied using Kennedy's classification which is the most widely accepted and universally followed classification of the partial edentulous state. ${ }^{9}$

It would also educate the people in the rural sector to be aware of their current oral health status and the various treatment options available for them based on their affordability and needs. This survey can also be helpful in planning various oral health care programs in rural areas by the private and public organizations to uplift the health and economy of the country.

\section{MATERIALS AND METHODS}

A descriptive point prevalence survey was conducted in rural population of Kancheepuram, Thiruvallur, and 


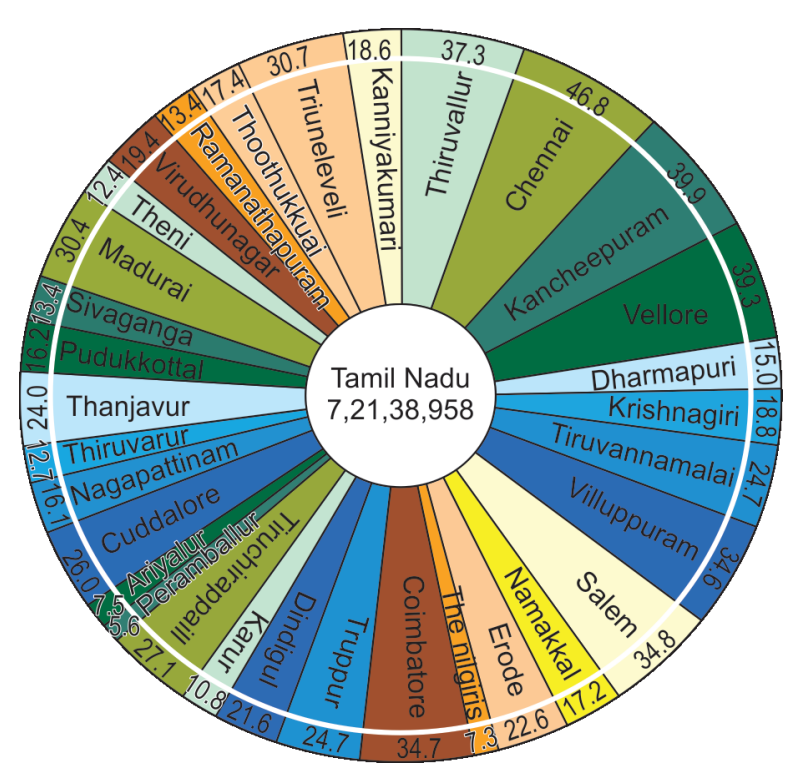

Graph 1: District-wise population distribution in the state of Tamil Nadu, South India

Vellore districts, Tamil Nadu, India. These districts were randomly chosen from the most populous districts in South India (Census 2011) (Graph 1). Men and women above 18 years of age and permanent residents of that district were included in the study. Subjects $<18$ years of age, completely edentulous patients, patients already been treated with functioning fixed prosthesis, uncooperative subjects, and individuals not native to those districts were excluded from the study. Ethical approval for the study was obtained from the Scientific Review Board and Institutional Human Ethical Committee of Saveetha University. The sample size was calculated based on the pilot study done in Saveetha University outpatient department for 1 month. The estimated sample size with power $80 \%$ was 4,000 . After screening of 2,000 samples, post hoc power analysis test was done and sample size was recalculated as 3,000 with a power of $80 \%$. The subjects are divided into three groups depending on their age: Group I - 18 to 30 years, group II - 31 to 50 years, and group III - 51 to 80 years. A nonprobability quota sampling method was used in the study. The survey was conducted from April to November 2011. About 150 to 300 individuals were screened in every visit during the day. The camp was set up in schools and panchayat office in the selected districts. Banners and pamphlets regarding our survey and free treatment were given to the people 1 week before our visit. A modified WHO questionnaire was used in this study to collect the desired data (Fig. 1). The WHO questionnaire format and guidelines on how to conduct an oral health survey is an important asset. It standardizes research methods and allows for comparison of results. ${ }^{10}$ The subjects were screened for missing teeth, tooth loss pattern, abutment evaluation, and treatment based on clinical examination and affordability was recorded.

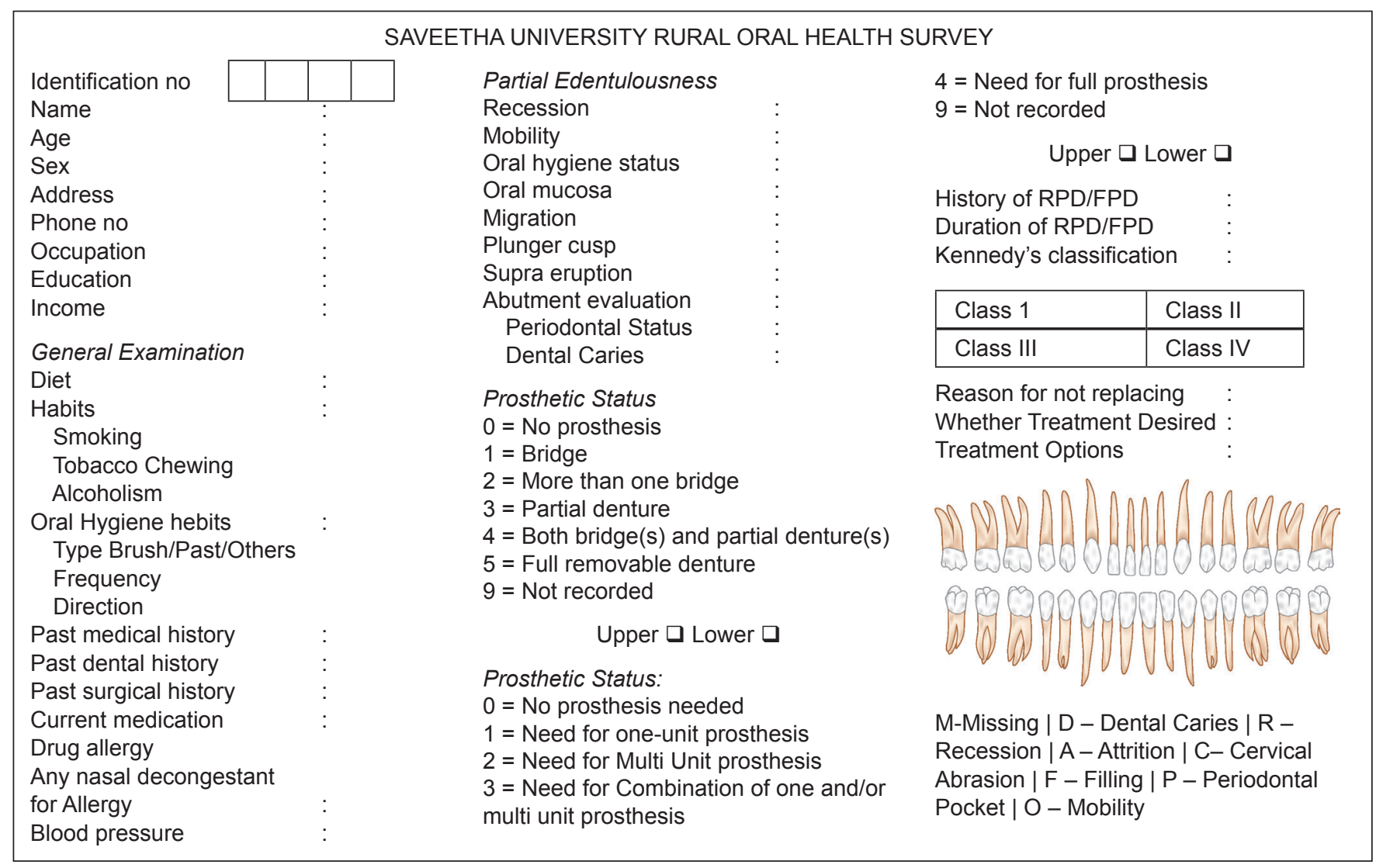

Fig. 1: Modified WHO questionnaire used in the data collection 


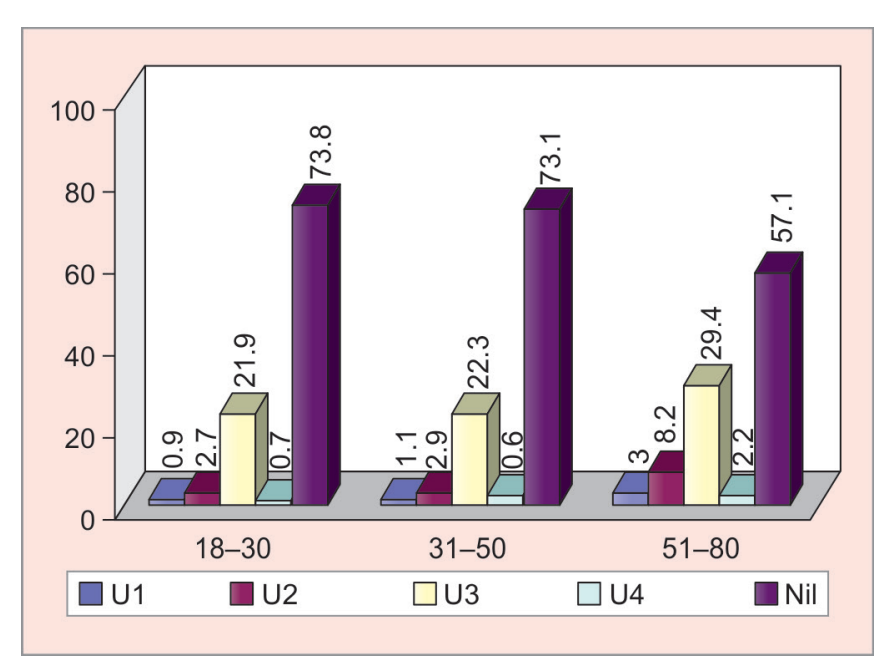

Graph 2: Prevalence of age-group wise partial edentulousness in maxilla (U: Upper class)

\section{RESULTS}

Out of 3,000 patients, 1,462 had tooth loss. The results showed that Kennedy's class III was the most commonly occurring type of tooth loss in all the three groups, maxilla (23.3\%) (Graph 2) and mandible (22.1\%) (Graph 3), followed by class II maxilla (3.7\%) and mandible (7\%), class I maxilla $(1.3 \%)$ and mandible $(1.4 \%)$, and class IV maxilla $(0.9 \%)$ and mandible $(0.3 \%)$. From the results, it was evident that tooth loss is more in men (58.2\%) compared with women (41.8\%) (Graph 4). Tooth loss was more in group III subjects compared with groups I and II. Most commonly occurring missing tooth was mandibular first molar.

Based on the clinical condition and tooth loss pattern, the subjects were given treatment options of fixed partial dentures (FPD), removable partial denture (RPD), complete dentures, and implant supported prosthesis. About 99.3\% of the patients preferred fixed type of prostheses; however, due to socioeconomic reasons, $56.2 \%$ of the people opted for FPD, 28\% for RPD, 14.1\% for implants, and $1.7 \%$ for complete dentures.

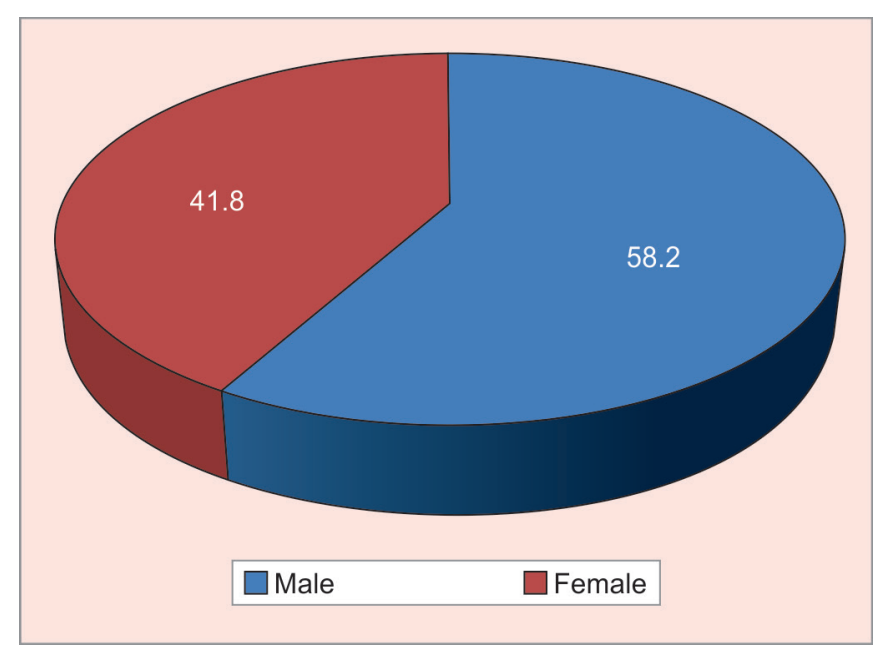

Graph 4: Tooth loss and sex

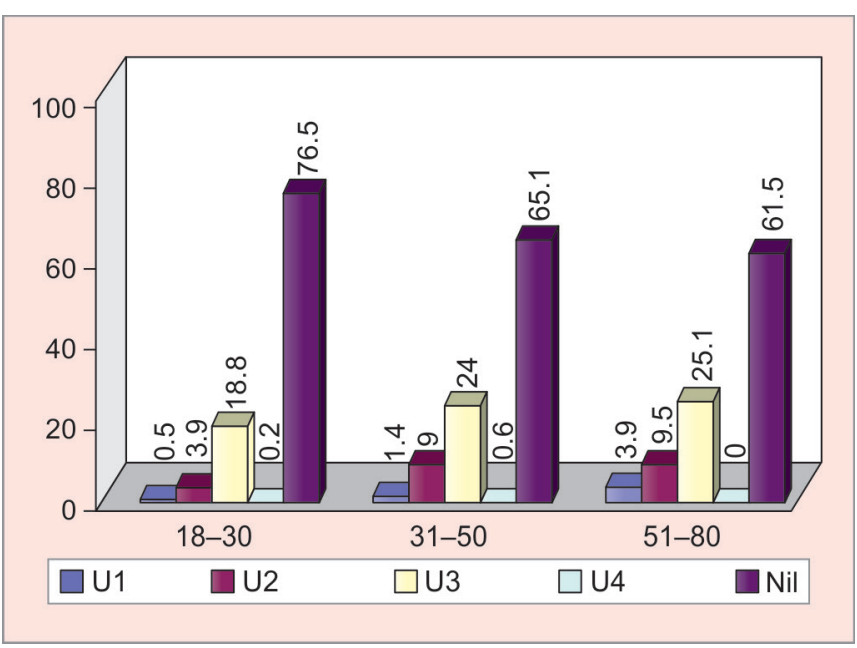

Graph 3: Prevalence of age-group wise partial edentulousness in mandible (U: Upper class)

\section{DISCUSSION}

The survey is a systematic method of collecting data from a population of interest. Point prevalence survey helps in identifying the occurrence of particular disease (or) condition in a particular period. ${ }^{11}$ The total prevalence of tooth loss was $48.7 \%$. The prevalence of partial edentulousness in Haryana was $47.4 \%$ in $2010^{12}$ and Chennai suburban population is $45.5 \% .{ }^{13}$ The results obtained are similar, but there can be an increase in the incidence of tooth loss if the study population was targeted to the older age group.

In our study, the most common reason for tooth loss was periodontal disease, especially in group III subjects, but in group I subjects, the common reason was dental caries. This is in accordance with studies done by AlShammari et $\mathrm{al}^{15}$ where caries was the primary reason for tooth loss in patients with age $<40$ years, whereas in patients with more than 40 years of age, periodontal disease was the most common reason.

Partially edentulous state was again more prevalent in group III subjects compared with groups I and II. This shows that tooth loss increases with age. This is in accordance with studies done by Madléna et $\mathrm{al}^{4}$ who reported that tooth loss is directly proportional to age. This could be due to systemic disease, poor oral hygiene, lack of education and awareness, and due to low socioeconomic status.

Tooth loss was more common in men (58.2\%) compared with women $(41.8 \%)$. Similar results were seen in study done by Rihs et $\mathrm{al}^{16}$ but not in accordance with study done by Kudo et al. ${ }^{8}$ This may be due to the fact that tooth loss pattern varies with race, ethnicity, and gender.

In all the three groups, Kennedy's class III partially edentulous state was the most prevalent type of tooth loss irrespective of the arch. However, when partially edentulous state in maxilla and mandible was compared, 
the prevalence was higher in maxilla $(23.3 \%)$ than in mandible $(22.1 \%)$. Similar results were seen in Iraqi population. ${ }^{16}$ The reason for this pattern of tooth loss is due to the development of oral health awareness among the population.

The most common missing tooth is the mandibular first molar. The reason for this is due to dental caries. Many studies have conclusively reported that the mandibular molars were the most severely affected teeth in the entire dentition due to dental caries since it is the first tooth to erupt. This could be the possible reason why mandibular molars are the most commonly missing tooth. ${ }^{17-19}$

In mandible and maxilla, most common missing teeth were the posteriors, and this was in accordance with the studies done by Locker et al. ${ }^{20}$ The type of edentulousness affects the individual's food choice and masticatory ability which in turn may affect the nutritional status of the individual, especially in older adults.

There is strong evidence that a diet high in fruits and vegetables protects our body against obesity, diabetes, cardiovascular disease, and some cancers. ${ }^{21}$ The recommended intake of fruits and vegetables is $400 \mathrm{gm} /$ day (WHO 2003). Thus, tooth loss will ultimately lead to poor dietary intake which in turn causes poor nutritional status. Masticatory performance and biting force are greater in dentate individuals followed by partially edentate and completely edentulous individuals. ${ }^{22}$ The subjects in all three study groups had missing posterior teeth, and in such partially edentulous subjects, biting force and masticatory ability is much lower compared with dentate individuals which was the prime concern in replacing the missing posterior teeth.

Enlargement of the tongue, reduction in the vertical dimension, and lower facial height of the individual are common sequalae of tooth loss, which are also confounding factors for obstructive sleep apnoea. ${ }^{23}$ Tooth loss is recognized as an individual risk factor for a range of systemic conditions, such as hypertension, stroke, cardiovascular disease, diabetes, and coronary heart disease. ${ }^{24-26}$

These individuals with a high percentage of tooth loss need prosthetic restorations to restore the form, function, and esthetics. Based on their clinical condition, the patients were educated about the different treatment options and almost $100 \%$ of them preferred fixed type of prosthesis. However, their preference changed based on the cost of the treatment. About $56.2 \%$ opted for FPDs, $28 \%$ for RPDs, $14.1 \%$ for implants, and $1.7 \%$ for complete dentures.

Limitations of our study are nutritional assessment could have been done to assess the nutrition and dietary intake of the people with tooth loss. Future studies could be done to study the sequalae of tooth loss and its correlation to systemic diseases.

\section{CONCLUSION}

Total prevalence of tooth loss is $48.7 \%$, and Kennedy's class III was the most common type of tooth loss. Men had a higher incidence of tooth loss compared with women. The loss of teeth was directly proportional to age. The main reason for tooth loss was caries and the most common tooth lost was mandibular first molar. By bringing about awareness of tooth loss, its sequalae, and available treatment options in a rural population, the dental needs of the community could be met leading to an overall improvement in their quality of life.

\section{ACKNOWLEDGMENTS}

Authors would like to thank Saveetha Dental College Faculty and the management for the intense support and guidance throughout the study. The authors also acknowledge the subjects from the community for their active participation.

\section{REFERENCES}

1. Marcus SE, Drury TF, Brown LJ, Zion GR. Tooth retention and tooth loss in the permanent dentition of adults: United States, 1988-1991. J Dent Res 1996 Feb;75 Spec No:684-695.

2. Yiengprugsawan V, Somkotra T, Seubsman SA, Sleigh AC, Thai Cohort Study Team. Oral health-related quality of life among a large national cohort of 87,134 Thai adults. Health Qual Life Outcomes 2011 Jun;9:42.

3. Adegboye AR, Fiehn NE, Twetman S, Christensen LB, Heitmann BL. Low calcium intake is related to increased risk of tooth loss in men. J Nutr 2010 Oct;140(10):1864-1868.

4. Madléna M, Hermann P, Jáhn M, Fejérdy P. Caries prevalence and tooth loss in Hungarian adult population: results of a national survey. BMC Public Health 2008 Oct;8(1):364.

5. Baba K, Igarashi Y, Nishiyama A, John MT, Akagawa Y, Ikebe K, Ishigami T, Kobayashi H, Yamashita S. Patterns of missing occlusal units and oral health-related quality of life in SDA patients. J Oral Rehabil 2008 Aug;35(8):621-628.

6. Oginni FO. Tooth loss in a sub-urban Nigerian population: causes and pattern of mortality revisited. Int Dent J 2005 Feb;55(1):17-23.

7. Ong G, Yeo JF, Bhole S. A survey of reasons for extraction of permanent teeth in Singapore. Community Dent Oral Epidemiol 1996 Apr;24(2):124-127.

8. Kudo Y, John MT, Saito Y, Sur S, Furuyama C, Tsukasaki H, Baba K. Oral health in the Japan self-defense forces - a representative survey. BMC Oral Health 2011 Apr;11:14.

9. Joshipura KJ, Willett WC, Douglass CW. The impact of edentulousness on food and nutrient intake. J Am Dent Assoc 1996 Apr;127(4):459-467.

10. Carr, AB.; McGivney, GP.; Brown, DT. McCracken's removable partial prosthodontics. 11th ed. St. Louis (MO): Elsevier Mosby; 2012. p. 19-24. 
11. Broadbent JM, Thomson WM, Poulton R. Progression of dental caries and tooth loss between the third and fourth decades of life: a birth cohort study. Caries Res 2006;40(6): 459-465.

12. Brodeur JM, Benigeri M, Naccache H, Olivier M, Payette M. Trends in the level of edentulism in Quebec between 1980 and 1993. J Can Dent Assoc 1996 Feb;62(2):159-160, 162-166.

13. Bansal V, Sogi GM, Veeresha KL. Assessment of oral health status and treatment needs of elders associated with elders' homes of Ambala division, Haryana, India. Indian J Dent Res 2010 Apr-Jun;21(2):244-247.

14. George B, John J, Saravanan S, Arumugham IM. Prevalence of permanent tooth loss among children and adults in a suburban area of Chennai. Indian J Dent Res 2011 Mar-Apr; 22(2):364.

15. Al-Shammari KF, Al-AnsariJM, Al-Melh MA, Al-Khabbaz AK. Reasons for tooth extraction in Kuwait. Med Princ Pract 2006 Mar;15(6):417-422.

16. Rihs LB, da Silva DD, de Sousa Mda L. Dental caries and tooth loss in adults in a Brazilian southeastern state. J Appl Oral Sci 2009 Sep-Oct;17(5):392-396.

17. Hatim NA, Muhammed SA, Hasan NH. Psychosocial profile of patient with missing teeth and refuses treatment. Al-Rafidain Dent J 2003:3(2):88-95.

18. Loesche WJ, Schork A, Terpenning MS, Chen YM, Kerr C, Dominguez BL. The relationship between dental disease and cerebral vascular accident in elderly United States veterans. Ann Periodontol 1998 Jul;3(1):161-174.
19. Inukai M, Baba K, John MT, Igarashi Y. Does removable partial denture quality affect individuals' oral health? J Dent Res 2008 Aug;87(8):736-739.

20. Locker D, Ford J, Leake JL. Incidence of and risk factors for tooth loss in a population of older Canadians. J Dent Res 1996 Feb;75(2):783-789.

21. Jagadeesan M, Rotli SB, Danabalan M. Oral health status and risk factors for dental and periodontal disease among rural women in Pondicherry. Indian J Community Med 2000 Jan-Mar;25(1);31-38.

22. Bradbury J, Thomason JM, Jepson NJ, Walls AW, Mulvaney CE, Allen PF, Moynihan PJ. Perceived chewing ability and intake of fruit and vegetables. J Dent Res 2008 Aug;87(8): 720-725.

23. Boretti G, Bickel M, Geering AH. A review of masticatory ability and efficiency. J Prosthet Dent 1995 Oct;35(2):183-189.

24. Ivanhoe JR, Cibirka RM, Lefebvre CA, Parr GR. Dental considerations in upper airway sleep disorders: a review of the literature. J Prosthet Dent 1999 Dec;82(6):685-698.

25. DesvarieuxM,Schwahn C, VölzkeH,Demmer RT, LüdemannJ, Kessler C, Jacobs DR Jr, John U, Kocher T. Gender differences in the relationship between periodontal disease, tooth loss, and atherosclerosis. Stroke 2004 Sep;35(9):2029-2035.

26. Taguchi A, Sanada M, Suei Y, Ohtsuka M, Lee K, Tanimoto K, Tsuda M, Ohama K, Yoshizumi M, Higashi Y. Tooth loss is associated with an increased risk of hypertension in postmenopausal women. Hypertension 2004 Jun;43(6): 1297-1300. 